\title{
Effet de la forme de présentation du foin sur son utilisation digestive chez le poney
}

\author{
JL Tisserand, F Faurie \\ INRA-ENESAD, Unité associée de Recherches Zootechniques, BP 1607, 21034 Dijon Cedex, France
}

Pour mesurer les effets éventuels de la forme de présentation du fourrage susceptibles de modifier son utilisation digestive nous avons expérimenté un foin de luzerne-dactyle de composition (MM 7,87 ; CB 36,33 ; MAT 14,39 $\% \mathrm{MS}$ ) présenté sous trois formes, haché $(\mathrm{H})$, aggloméré après hachage (A1) ou aggloméré après broyage à la grille de $1,5 \mathrm{~mm}(\mathrm{~A} 2)$ dont les pourcentages de particules inférieures à 0,8 $\mathrm{mm}$ étaient respectivement de 38,66 et $75 \%$.

Une première étude a été réalisée sur 4 poneys adultes mâles entiers d'un poids vif moyen de $172 \mathrm{~kg}$ pour mesurer la digestibilité in vivo selon la méthode décrite par MartinRosset et al (1984, Le cheval INRA-Paris, 209338) au cours de 3 périodes successives de 3 semaines d'accoutumance suivie de 6 jours de mesure. Les quantités distribuées, les refus éventuels et les fèces ont été pesés quotidiennement et individuellement. Ils sont échantillonnés pour doser la teneur en matières minérales et en matières azotées ainsi qu'en paroi selon la méthode de $V$ an Soest, (1963, J Ass Agric Chem, 46, 829-835), la quantité d'eau de boisson a été contrôlée.

4 poneys adultes mâles porteurs d'une canule permanente du caecum pesant en moyenne $178 \mathrm{~kg}$ de poids vif, ont permis d'évaluer l'activité cellulolytique caecale par la méthode des sachets de nylon in situ (Demarquilly et Chenost, 1960, Ann Zootech, 18, 419-432) mesurée sur le foin sur une période de $24 \mathrm{~h}$ avec 4 répétitions par période et par sujet après 2 semaines d'accoutumance ainsi que le taux d'acides gras volatils (AGV) dans le contenu du caecum à l'aide de la moyenne de 3 points de cinétique à jeun 4 et 8 heures après le repas du matin avec 2 répétitions par temps et par sujet pour chaque période.

L'agglomération a légèrement modifié la composition chimique des aliments :

A1 (MM 10,20; CB 31,71; MAT $16,6 \%$ MS)

A2 (MM 9,74; CB 31,38 ; MAT $15,5 \%$ MS).

Pour des niveaux d'ingestion identiques, la digestibilité de la matière organique (DMO) est plus élevée après l'agglomération mais seule celle des parois végétales (DNDF, DADF) est significative dans le cas de A2. L'eau consommée par $\mathrm{kg}$ de MS augmente avec l'agglomération.

L'activité cellulolytique in situ n'est pas modifiée ni le taux d'AGV dans le caecum mais l'agglomération modifie significativement le rapport $\mathrm{C} 2 / \mathrm{C} 3$ en faveur de la production d'acide acétique.

Ces résultats montrent que la forme de distribution de foin peut modifier son utilisation digestive.

\begin{tabular}{|c|c|c|c|}
\hline Régime & $\mathrm{H}$ & A1 & $\mathrm{A} 2$ \\
\hline \multicolumn{4}{|l|}{ Digestibilité in vivo } \\
\hline Ingestion g MS/P0,75 & $56,4 \pm 0,5^{a}$ & $56,1 \pm 2,1^{a}$ & $56,8 \pm 2,3^{a}$ \\
\hline DMO & $55,0 \pm 3,5^{a}$ & $58,3 \pm 1,6^{a}$ & $60,7 \pm 2,2^{a}$ \\
\hline DNDF & $46,0 \pm 7,1$ ab & $47,2 \pm 2,5^{a}$ & $51,9 \pm 3,0^{b}$ \\
\hline DADF & $43,9 \pm 7,2^{\mathrm{ab}}$ & $43,8 \pm 2,7^{a}$ & $51,6 \pm 3,1^{b}$ \\
\hline Eau consommée l/kg MS & 4,36 & 5,1 & 6,5 \\
\hline \multicolumn{4}{|l|}{ Etude dans le caecum } \\
\hline \multicolumn{4}{|l|}{ Activités cellulolytiques } \\
\hline Dégradabilité MS & $57,7 \pm 1,8^{a}$ & $58,5 \pm 2,1 \mathrm{a}$ & $57,7 \pm 1,4 a$ \\
\hline Dégradabilité NDF & $44,8 \pm 2,9 a$ & $43,3 \pm 2,2^{a}$ & $42,9 \pm 1,6^{a}$ \\
\hline Dégradabilité ADF & $43,5 \pm 2,7 a$ & $41,9 \pm 1,6^{a}$ & $41,8 \pm 1,5^{\mathrm{a}}$ \\
\hline \multicolumn{4}{|l|}{ Acides gras volatils } \\
\hline Totaux $(g / l)$ & $2,62^{a}$ & $3,12^{a}$ & $2,66^{a}$ \\
\hline Acétique \% & $52,2^{a}$ & $68,1^{b}$ & $69,8^{b}$ \\
\hline Propionique \% & $34,1^{a}$ & $21,1^{b}$ & $19,8^{b}$ \\
\hline
\end{tabular}

Les résultats d'une même ligne affectée de la même lettre ne sont pas significativement différents 